\title{
Synthesis of Branched Polypropylene by a Reactive Extrusion Process
}

\author{
D. Graebling \\ É col e Supérieure de Plasturgie Laboratoi re de Recherche Puridisciplinaire en Plasturgie, \\ BP 807, 01108 Oyonnax, France \\ Received May 31, 2001; Revised Manuscript Received J anuary 28, 2002
}

\begin{abstract}
Polypropylenes with long chain branches were obtained using reactive extrusion in the presence of peroxide, a polyfunctional acrylate monomer and a co-reactant: a sulfide compound such as thiuram disulfide. By thermal decomposition, the thiuram disulfide gives two dithiocarbamate radicals. These radicals can be reacted with the macroradical PP, and this reaction is reversible. They induce a decrease in the instantaneous concentration of free radicals, favor the branching, and thus limit the effect of the $\beta$-scission. The long chain branches structure was confirmed by dynamic viscoelastic measurements and thermal analysis.
\end{abstract}

\section{Introduction}

Chemical reactions involving polymer are usually carried out in a solvent in order to obtain the desired modification, such as functionalization, grafting, or compatibilizing polymer blends. These reactions may also be performed, with a twin-screw extruder, in onestep polymer processing. In this case, the extruder will be the chemical reactor, which may involve problems of high temperature, viscosity, etc.

Polypropylene or PP is an useful thermoplastic for a wide range of applications, neverthless, its utilization can be enhanced by grafting or blending. The PP, prepared by Ziegler-Natta or metallocene catalysis, has a linear structure and its rheological behavior, in a steady uniaxial elongational flow, is characterized by a troutonian behavior:

$$
\eta_{\mathrm{e}}=3 \eta_{0}
$$

where $\eta_{\mathrm{e}}$ and $\eta_{0}$ are respectively the elongational viscosity and Newtonian viscosity.

Unfortunately, this rheological behavior is not fitting for the processes where el ongational flows are dominant, such as blowing, thermoforming, or foaming. The polymer liquid with a strain hardening in elongational flow is more appropriate for these processes. ${ }^{1,2}$ The high melt strength or HMS is obtained for materials with long side branches (polyethylene) or for high molecular weight (polystyrene).3,4 With a linear chain, two approaches allow the transition of the flow regime for the same deformation rate: an increase of molecular weight or the grafting of long branches. The grafting is preferable to limit the increase of the shear viscosity. ${ }^{5}$ The branched polypropylenes show strain hardening in el ongational flow: polypropylene high melt strength or PP-HMS. ${ }^{6-12}$ They are characterized by a large molecular weight distribution and very long terminal relaxation time. According to Gaylor, the PP-HMS is characterized by a bimodal molecular weight distribution, wherein the higher molecular weight fraction contains branched polymer. ${ }^{13}$

The aim of this work was to obtain branched PP by a reactive extrusion process. The reactivity of PP stems from its hydrogen atoms al ong the hydrocarbon skeleton that are subjected to free radical attack. The free radicals, generated by peroxide decomposition, abstract the labile proton on the tertiary carbon sites. The macroradicals PP will undergo either degradation leading to chain cleavage by $\beta$-scission or grafting. Furthermore, due to the high unstability of tertiary macroradicals, the degradation process is extremely fast at high temperature ( $T$ > melting temperature). Thus, stabilizing and consuming macroradicals in favor of grafting are almost the means to reduce the chain degradation. It is necessary to build the branched molecular structure from that destroyed by $\beta$-scission via a polyfunctional monomer (F igure 1). The envisaged chemical modification must favor the grafting reaction between the polymer chains over the $\beta$-scission reaction. Another difficulty of free radical grafting arises from the competition between monomer grafting and homopolymerization.

Polypropylene with long side branches can be obtained with a new chemical approach. We used a triacrylate monomer and a sulfide compound such as the tetraethyl thiuram disulfide, to reduce the effect of the $\beta$-scission. ${ }^{14}$ These molecules are known as iniferter compounds.

\section{Chemical Modifications of Polypropylene}

Chodák and co-workers studied the cross-linking of atactic and isotactic PP in the presence of polyfunctional monomers such as diallyl maleate or pentaerythrityl tetramethacrylate. ${ }^{15}$ Benzoyl peroxide and cumyl peroxide were used as initiator. They have shown that the cross-linking of the isotactic PP is higher than the atactic PP. According to the authors, the molecular weight of the isotactic PP facilitates cross-linking. The benzoyl peroxide is more efficient. With this initiator, the pentaerythrityl tetramethacrylate al lows a relative high percentage of gel at low concentrations. The reason is the high reactivity of this coagent. On the contrary, the less reactivity of diallyl maleate yields lower gel contents at low concentrations but by increasing its concentration, the isotactic polymer reaches a higher degree of gel.

Borsig et al. investigated the role of a polyfunctional monomer such as pentaerythritol tetraallyl ether, with peroxide, in raising the cross-linking efficiency of PP in the solid state at $170{ }^{\circ} \mathrm{C} .16$ Polyfunctional monomer grafted to PP is an active site for trapping another macroradical and for formation of a cross-linked structure by connecting the chains. 


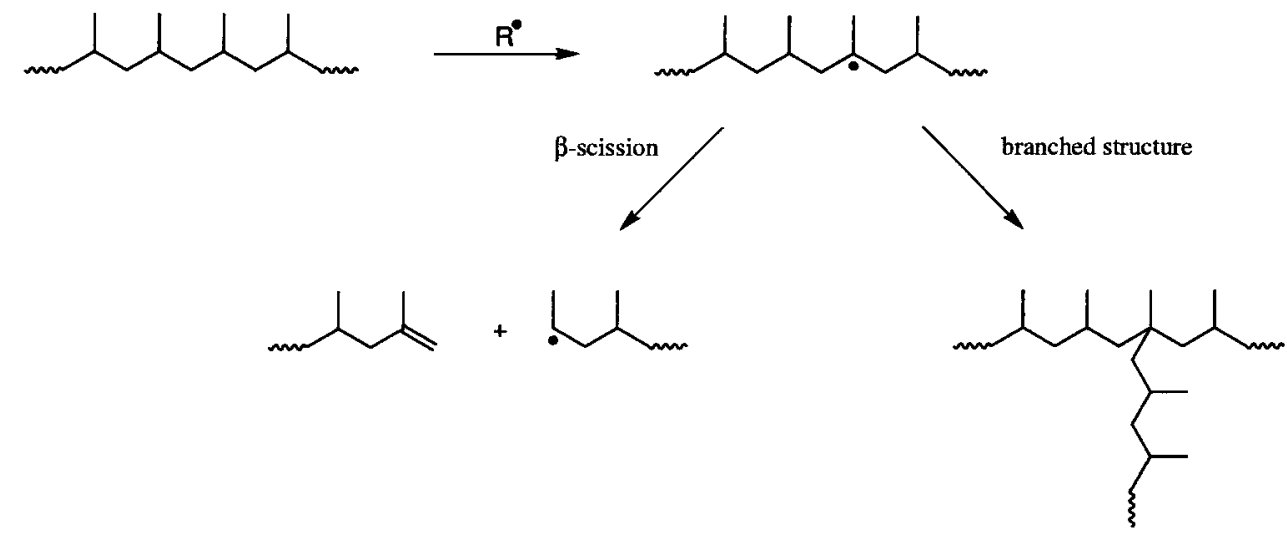

Figure 1. Competition between $\beta$-scission and polymer cross-linking.

Xiaochuan et al. have prepared branched and crosslinked PP by a reactive extrusion process at $200{ }^{\circ} \mathrm{C}$ using 2,5-dimethyl-2,5-di(tert-butyl peroxy)hexane as initiator and pentaerythritol triacrylate as monomer. ${ }^{17}$ Three concentrations of peroxide $(0.02,0.06$, and $0.1 \%)$ and four concentrations of monomer were studied. The low concentrations of peroxide limit the degradation of PP by $\beta$-scission.

The cross-linking of PP with a peroxide was investigated by Chodák and Zimányonvá in the temperature range $10-220^{\circ} \mathrm{C} .{ }^{18}$ The process was initiated by radicals formed either by thermal or by photo decomposition of dicumyl peroxide. The concentration of cross-links decreases then the temperature increases at any peroxide concentration. The efficiency of the thermal crosslinking increases slightly with peroxide concentration at any temperature. When the reaction was initiated by irradiation, the efficiency is highest at $65-80{ }^{\circ} \mathrm{C}$.

Simúkova and al. have obtained a cross-linked atactic PP by using dicumyl peroxide with sulfur at 130-150 ${ }^{\circ}$ C. ${ }^{19}$ In 1985, Čapla and al. studied the influence of sulfur and its mixtures with polyfunctional monomers on the efficiency of cross-linking of PP. 20 The dicumyl peroxide was used as initiator. At $170{ }^{\circ} \mathrm{C}$, the gel formation is increased by addition of sulfur. The optimun of the formation of gel is reached for a dicumyl peroxide and sulfur ratio close to 1 . The sulfur is an effective coagent of PP cross-linking initiated by peroxides. The addition of polyfunctional monomers, such as divinyl benzene, diallyl maleate, or triallyl cyanurate, etc., yields no gel after $1 \mathrm{~h}$ at $170{ }^{\circ} \mathrm{C}$. The addition of equimolar amounts of sulfur with respect to initiator increases the gel content. When the pentaerythritol tetraallyl ether is used as coagent in the presence of sulfur, the gel content of polypropylene decreases to a great extent.

The cross-linking of PP initiated by peroxides conducted in the presence of thiourea and its derivatives was studied by Borsig et al. ${ }^{21}$ This work has shown that thiourea is an efficient coagent of cross-linking in the temperature range $170-200^{\circ} \mathrm{C}$. I ts efficiency is significantly dependent on the ratio of peroxide to thiourea. But among the studied peroxides only tert-butyl perbenzoate and dibenzoyl peroxide exhibit efficiency in the cross-linking reaction at concentrations under $0.2 \mathrm{~mol} /$ $\mathrm{kg}^{-1}$. However, dicumyl peroxide and 2,5-dimethyl-2,5di(tert-butyl peroxy)hexane are inefficient at these concentrations if thiourea is used as coagent. The derivatives of thi ourea such as diphenylthiourea, $N^{\prime}, N^{\prime}-$ thiourea, and dibutylthiourea are less efficient than thiourea. The authors were found by analysis of the resulting gel that only sulfur participates in the formation of the polymer network.

The peroxide cross-linking of isotactic and syndiotactic PP was investigated by $Y u$ and Zhu. ${ }^{22}$ Two peroxides were used as initiator: the tert-butyl perbenzoate and the dicumyl peroxide. The experiments realized at 160 ${ }^{\circ} \mathrm{C}$ have shown that the isotactic PP having a higher cross-linking efficiency. By electron spin resonance, they have proved that the peroxide radicals attack for the two PP, the PP skeleton at the same position. A lower radical concentration was observed in syndiotactic $P P$ as compared with isotactic PP having the same peroxide concentration. According to the authors, this point is believed to be responsible for the lower cross-linking efficiency found with the syndiotactic PP.

In a patent application filed on behalf of the Himont Co. by De Nicola, modification in the solid state of PP is made with peroxide in the absence of oxygen in order to obtain branched macromolecules and gel-free polymer. ${ }^{23}$ This modification is realized in several steps at temperatures ranging from 70 up to $150{ }^{\circ} \mathrm{C}$, therefore at temperatures below the melting point of $\mathrm{PP}$, in the absence of oxygen. Two types of peroxide are used, one decomposing at low temperature (half-life time $\approx 30$ $\mathrm{s} / 100^{\circ} \mathrm{C}$ ), the other at higher temperature (half-life time $\approx 30 \mathrm{~s} / 135^{\circ} \mathrm{C}$ ). No coupling agent was used.

The electron beam irradiation of linear PP have been used to prepare a PP with long chain branches or PPHMS. 24 The radiation leads to a hydrogen abstraction and the lifetime of PP backbone radicals is so long under the reaction conditions-inert atmosphere and low temperature-that the radical combination to long chain branches can occur. For example, the weight-average molecular mass is 298000 before irradiation with a 6 Mrad electron beam and 1250000 after. ${ }^{24}$ Lucas et al. have been investigated the cross-linking of a propyleneethylene random copolymer irradiated with a $\gamma$ or an electron beam of ionizing radiation in air.25 The efficiency of cross-linking was determined by refluxing in boiling xylene for $12 \mathrm{~h}$. The gel content goes to $7.1 \mathrm{wt}$ $\%$ with $10 \mathrm{Mrad} \gamma$ radiation. Saito and coauthors have studied the cross-linking of PP irradiated with an electron beam under nitrogen in the presence of 1,6hexanediol diacrylate used as coagent. ${ }^{26}$ The crosslinking agent was added to the PP powder with a Henschel mixer for $3 \mathrm{~min}$. After irradiation, the blend was heat-treated in the oven at $135^{\circ} \mathrm{C}$ for $30 \mathrm{~min}$.

In a European patent, Braga and Ghisellini have obtained a mixture of cross-linked and non-cross-linked PP by a reactive extrusion process with a peroxide and a cross-linking agent. ${ }^{27}$ These agents are furane deriva- 

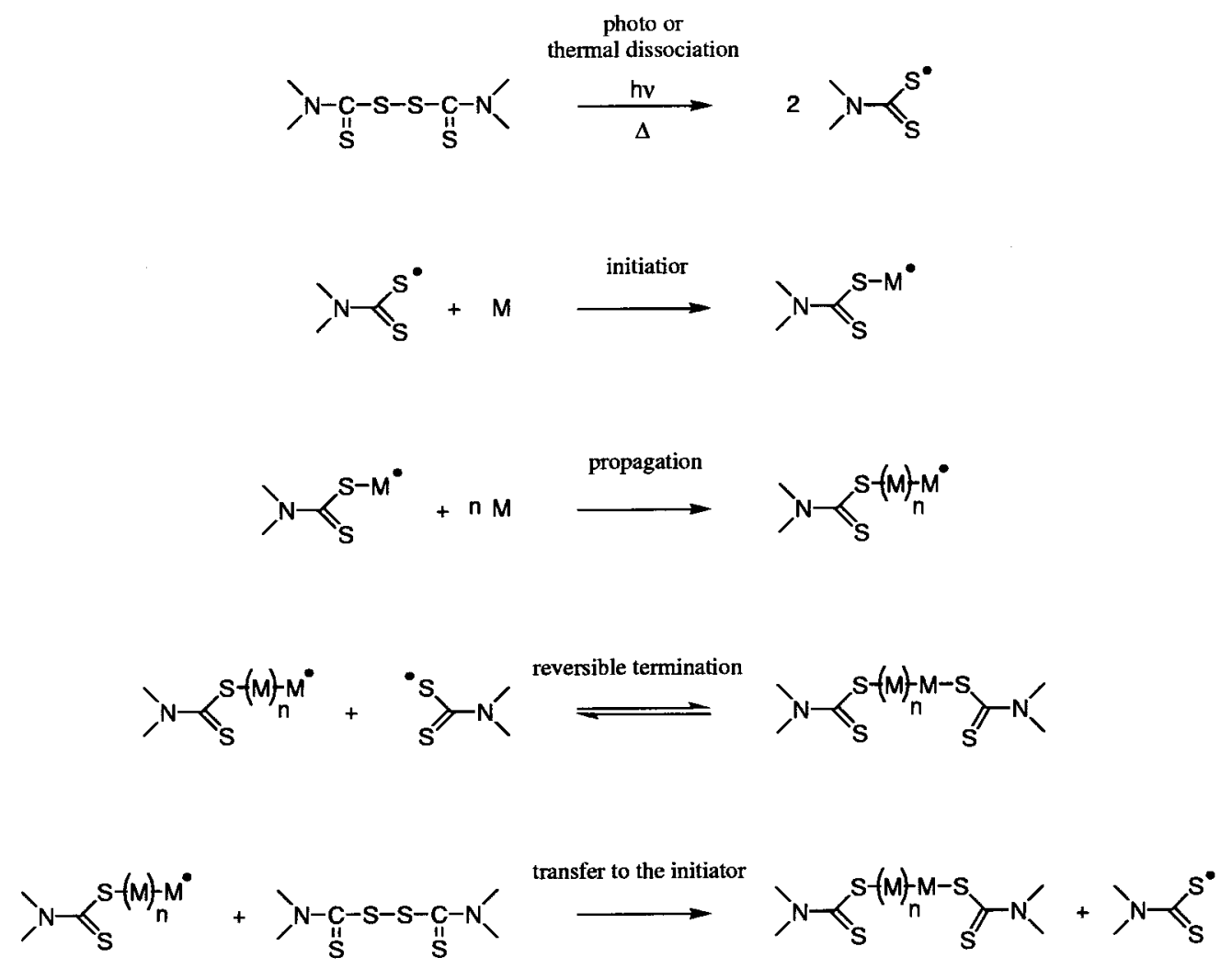

Figure 2. Polymerization with iniferter.

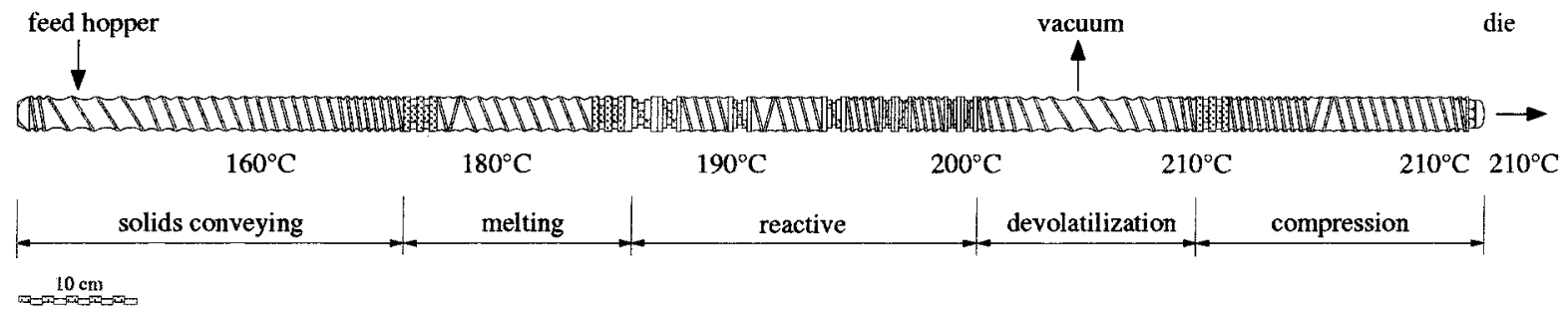

Figure 3. Screw profile of the co-rotating twin screw extrudeur.

tives such as 1,5-difurfuryl-1,4-pentadiene-3-one, difurfuraldazine, etc. The value of $71 \%$ of cross-linked PP is found for a formulation with 9 parts of peroxide by weight and 1.3 parts of difurfuraldazine by weight. Recently, new furfuryl compounds have been employed by Romani and co-workers to obtained cross-linked PP. 28

Yu et al. have been prepared branched PP with 2,5dimethyl-2,5-di(tert-butyl peroxy)hexane as initiator and pentaerythritol tetraacrylate as cross-linking agent and stabilizer. ${ }^{29}$ The transient recoverable strain measurements of modified PP indicate a increasing of elasticity due to the creation of branched structure.

PP with long chain branches were obtained using reactive extrusion in the presence of peroxydicarbonates ${ }^{30-31}$ without cross-linking coagent. ${ }^{32-33}$ The amount of Iong chain branches can be controlled by the type of peroxydicarbonates used. Lagendijk and coauthors have studied the efficiency of peroxides by rheological measurements. The blends of linear and long chain branches PP show a strain hardening in the elongational flow. The long chain branches structure was confirmed by high-temperature size exclusion chromatography.

A new method was proposed by Lu and Chung to prepare long chain branched PP with a relatively welldefined molecular structure. ${ }^{34}$ The chemistry involves a graft-onto reaction between a maleic anydride grafted
PP and several amine group terminated PPs. The formed PP with long chain branches has an imide linkage that connects the PP backbone and each PP side chain.

\section{Polypropylene Modifications by Addition of Polyethylene}

The addition of polyethylene or PE during the chemical modification of PP can be envisaged as a way of reducing the $\beta$-scission. Borsig studied the cross-linking of PP/PE blends at all concentration ranges of polymer, with a peroxide and pentaerythritol tetraallyl ether as a polyfunctional monomer. ${ }^{35}$ This co-agent seems more reactive with $P E$ than with $P P$.

Yu studied the effect of the peroxide concentration on the rheological behavior and weight distribution of PP/ LDPE (Iow-density PE) blends. ${ }^{36}$ The peroxide used was 2,5-dimethyl-2,5-di(tert-butyl peroxy)hexane. A blend of $\mathrm{PP} / \mathrm{LDPE} 75 / 25$ is characterized by strain hardening as a result of partial cross-linking of the LDPE phase.

Chodak used, in the case of PP/LDPE blends, a peroxide with a quinone which slightly delays the crosslinking of the PE and activates the cross-linking process of PP. 37

In the solid state, the photo-cross-linking by a photoinitiator xanthone of LDPE/PP blends is increasing 

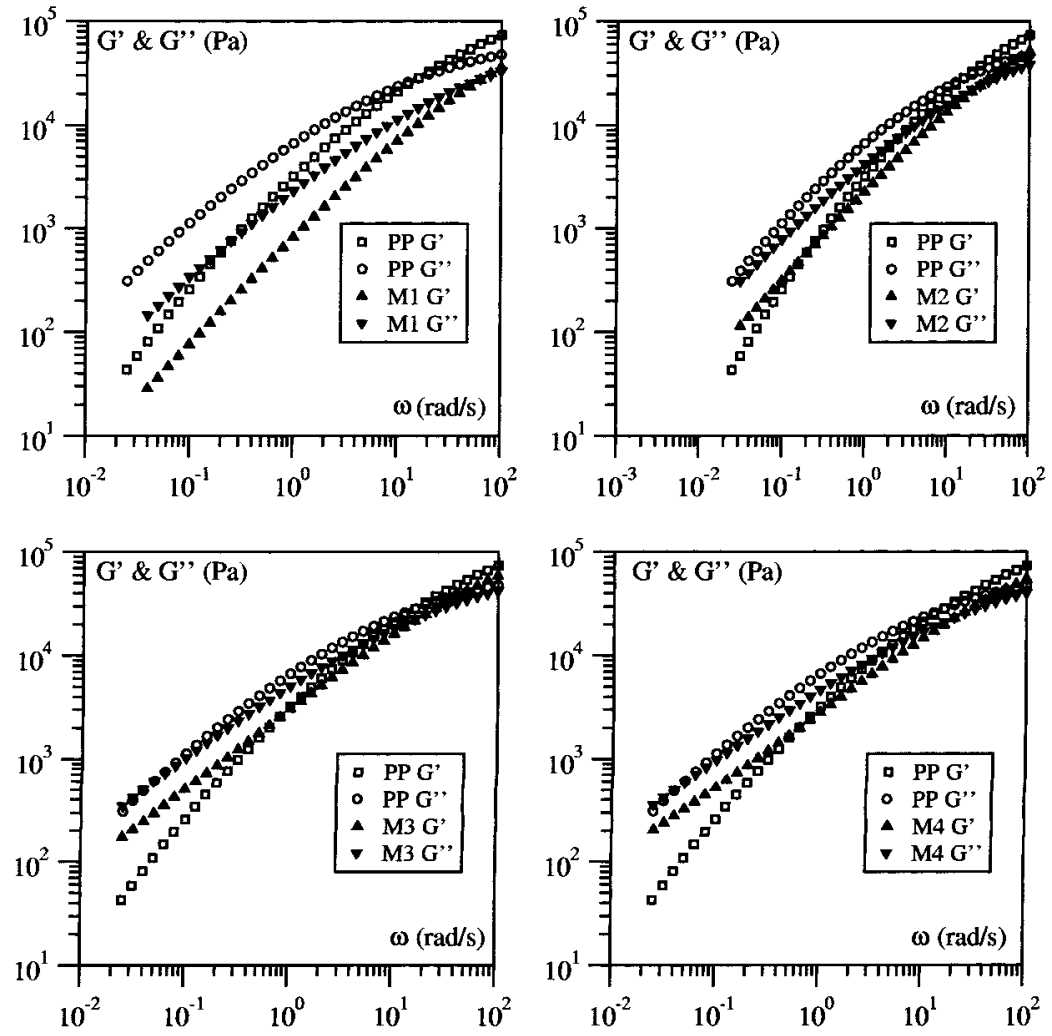

Figure 4. Dynamic moduli vs frequency. Polypropylene and polypropylene-modified $\mathrm{M} 1$ to $\mathrm{M} 4$ at $180{ }^{\circ} \mathrm{C}$.

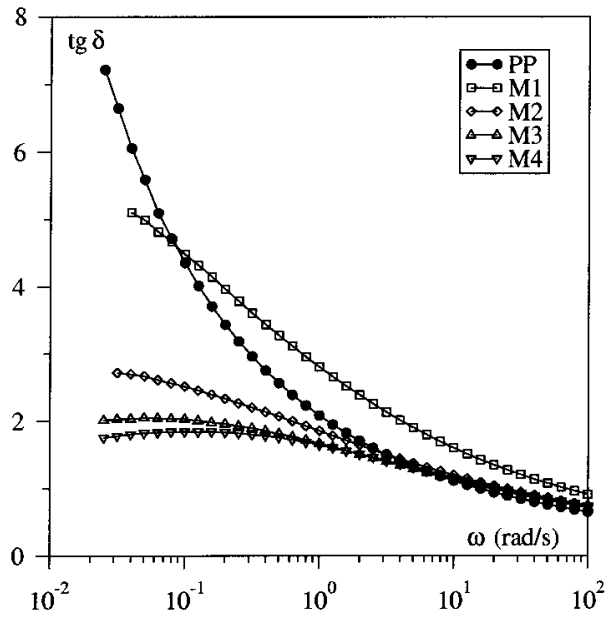

\section{Chemistry of Thiuram Disulfides}

The term of iniferter was proposed by Otsu et al. in 1982 to explain the properties of molecules such as phenylazotriphenylmethane, phenyl phenylazosulfide, alkyl perbenzoate, alkyl thiuram, etc., used in radical polymerization of vinyl monomer. ${ }^{41}$ These molecules are free radical initiators, transfer agents, and terminators or iniferters. Figure 2 shows the thermal and the photopolymerization of vinyl monomer $M$ by a tetraalkyl thiuram disulfide. The thiuram disulfides are classically used as iniferter for synthesizing block copolymers or telechelic polymers, ${ }^{42-44}$ and as accelerators in the vulcanization of natural rubber. ${ }^{45}$

The free radical initiation, chain transfer, and chain termination properties of thiuram disulfides have been identified first, by Ferrington and Tobolsky. ${ }^{46}$ They have studied the kinetics of the polymerization of styrene and methyl methacrylate thermally initiated by tetramethyl thiuram disulfide (TMTDS).

Kern has investigated the thermal and photopolymerization of some monomers, acrylonitrile, methyl acrylate, methyl methacrylate, styrene, etc., with disulfides and thiol compounds. ${ }^{47}$ In the case of TMTDS, he has shown that the conversion rate is much lower with methyl acrylate than with methyl methacrylate.

Otsu has shown that the methyl diethyldithiocarbamate has a photoinitiator in the polymerization of styrene. He observed that the polymer synthesized in the presence of tetraethyl thiuram disulfide (TETDS) are endcapped at both termi nals with dithiocarbamates halves. It was observed that the dithiocarbamate fragment can undergo reversible photodissociation, giving rise to an alkyl radical and a dithiocarbamate radical. This property is used to obtain block copolymers. For example, a triblock copolymer poly(MMA-S-MMA) was synthesized in two steps. The polystyrene with terminal 

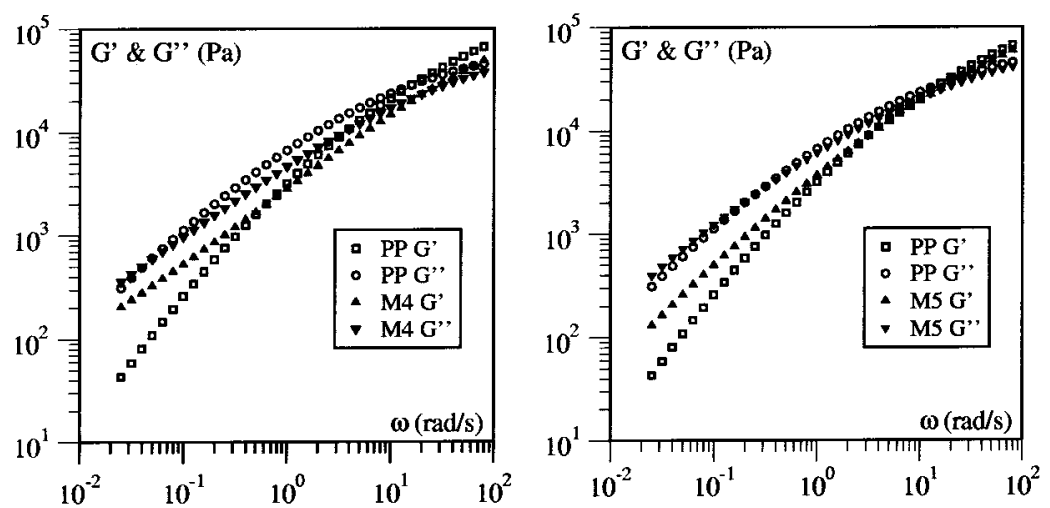

Figure 6. Dynamic moduli vs frequency. Polypropylene and polypropylene-modified M4 and M5 at $180{ }^{\circ} \mathrm{C}$.

dithiocarbamate functions was prepared by thermal polymerization with TETDS. The copolymer was obtained by photopolymerization of functionalized polystyrene in the presence of methyl methacrylate. ${ }^{48}$ I moto et al. have obtained with the same approach a styrenevinyl alcohol block copolymer by saponifying of the styrene-vinyl acetate block copolymer. ${ }^{49}$

In 1958, Ferrington and Tobolsky have explained the retarding effect of TMTDS in the presence of the initiator azobisisobutyronitrile in the polymerization of methyl methacrylate. ${ }^{50}$ This effect is due to the creation of polysulfide radical species and the initiation throught the intermediate radical RS .

Otsu et al. have studied the bulk polymerization of styrene, methyl methacrylate, acrylonitrile, vinyl acetate, and vinylidene chloride with several polysulfides as polymerization initiators. Under thermal conditions, the rate of polymerization of these monomers and initiators have been compared to two classical initiators: azobisisobutyronitrile and dibenzoyl peroxide. Like Kern, they have found that the tetraalkyl thiuram disulfides are excellent thermal initiators in the polymerization of styrene and methyl methacrylate, but the rate of conversion is much lower than with the classical initiators. However, these molecules are ineffective with the others monomers. The polysulfides such as dibenzoyl disulfide, dithiobenzoyl disulfide, dithiobis(benzothiazole), etc. cannot be considered as thermal initiators. All the polysulfide compounds were excel lent photoinitiators for these monomers. ${ }^{51-52}$

Barton and Bevington have been prepared several polystyrenes with TETDS Iabel ed with ${ }^{14} \mathrm{C}$ as photoinitiator. Polystyrenes prepared using TETDS label ed with ${ }^{14} \mathrm{C}$ in the ethyl groups contain the same number of labeled end groups as polymer prepared similarly using TETDS label ed with ${ }^{14} \mathrm{C}$ in the CS groups. ${ }^{53}$ This result indicates that the polymers do not contain $\mathrm{Et}_{2} \mathrm{~N}$ end groups formed result of the degradation of dithiocarbamate groups with production of carbon disulfide. The thiuram compound initiates polymerization with the dithiocarbamate radical and this radical is produced also during transfer to initiator. ${ }^{54}$

In 1982, Otsu et al. suggested that the photopolymerizations of vinyl monomers, stryrene, and methyl methacrylate, with organic sulfur compounds as photoinitiator, proceed via a living mechanism. ${ }^{55-59}$ Lambrinos et al. have shown that the polymerization of n-butyl acrylate with a thiuram disulfide photoinitiator is not strictly living. ${ }^{60}$ The alkyl dithiocarbamate reduces the rate of thermal polymerization of n-butyl acrylate but allows some control of molecular weight. This result has been explained by the degradative transfer or transfer between a macroradical and the chain with dithiocarbamate end group. ${ }^{61}$

In the vulcanization of natural rubber, the thiuram disulfide is used as a sulfur donor. ${ }^{45}$ Tetramethyl thi uram disulfide reacts exothermi cally with zinc oxide at $136-147^{\circ} \mathrm{C}$ to form zinc dimethyl dithiocarbamate, zinc dimethyl thiocarbamate and sulfur via a ionic mechanism. ${ }^{62}$ The tetramethyl thi uram disulfide forms transitory thiuram polysulfides when heated at $145^{\circ} \mathrm{C}$ via a radical process. ${ }^{63-65}$ The final products of thermal decomposition were carbon disulfide, tetramethyliuorea ans sulfur. With zinc oxide, the rate of their formation is slow. In fact, the both free radical and ionic mechanism are taking place simultaneoustly and that depends on the vulcanization process.

\section{Experimental Section}

5.1. Samples Preparation. Modified polypropylenes were prepared in a Werner \& Pfleiderer ZSK 30 intermeshing corotating twin screw extruder with a 42:1 length-to-diameter ratio. For all formulations, we used the same screw configuration (F igure 3). The total feeding rate of polymer was $5 \mathrm{~kg} / \mathrm{h}$ and the screw rotating speed $150 \mathrm{rpm}$ which corresponded to a residence time of $180 \mathrm{~s}$. The temperature in the first zone was set to a temperature of $160{ }^{\circ} \mathrm{C}$ and to a temperature of $210{ }^{\circ} \mathrm{C}$ for the die. A devolatilization zone was placed prior to the pumping zone close to the die for removing small molecules such as decomposition products of peroxide. Extrudates were cooled in water and then pelletized.

Powder of plain unstabilized polypropylene was supplied by Solvay company: polypropylene homopolymer ELTEX HL 001 $P$. The number-average mol ecular mass, $M_{n}$, and the weightaverage molecular mass, $M_{w}$, were respectively 30000 and 324000 before extrusion.

The free radical initiator was 2,5-dimethyl-2,5-di(tert-butyl peroxy)hexane or DHBP45 from Interox. The peroxide was dispersed at 45 wt $\%$ in $\mathrm{CaCO}_{3}$. The half-life of this peroxide is $1 \mathrm{~min}$ at $190{ }^{\circ} \mathrm{C}$.

Trimethylol propane triacrylate or TMPTA (Aldrich) was used as a monomer.

Four sulfide compounds that were used are listed in Table 1. These products were supplied by Aldrich.

All products were used without further purification. The formulations of modified polypropylenes are given in Table 2.

The products were added to the pol ypropylene powder ( 250 g) in a $500 \mathrm{~mL}$ beaker. The premix and $2750 \mathrm{~g}$ of polypropylene powder were tumble-mixed at room temperature and then placed in a weight-loss feeder.

5.2. Rheological Measurements. The dynamic measurements were carried out on a Rheometric Scientific ARES mechanical spectrometer using a parallel-plate geometry (diameter of sample: $25 \mathrm{~mm}$ ). The experimental temperature was measured with a precision of $\pm 0.1{ }^{\circ} \mathrm{C}$ (Pt100 thermo- 

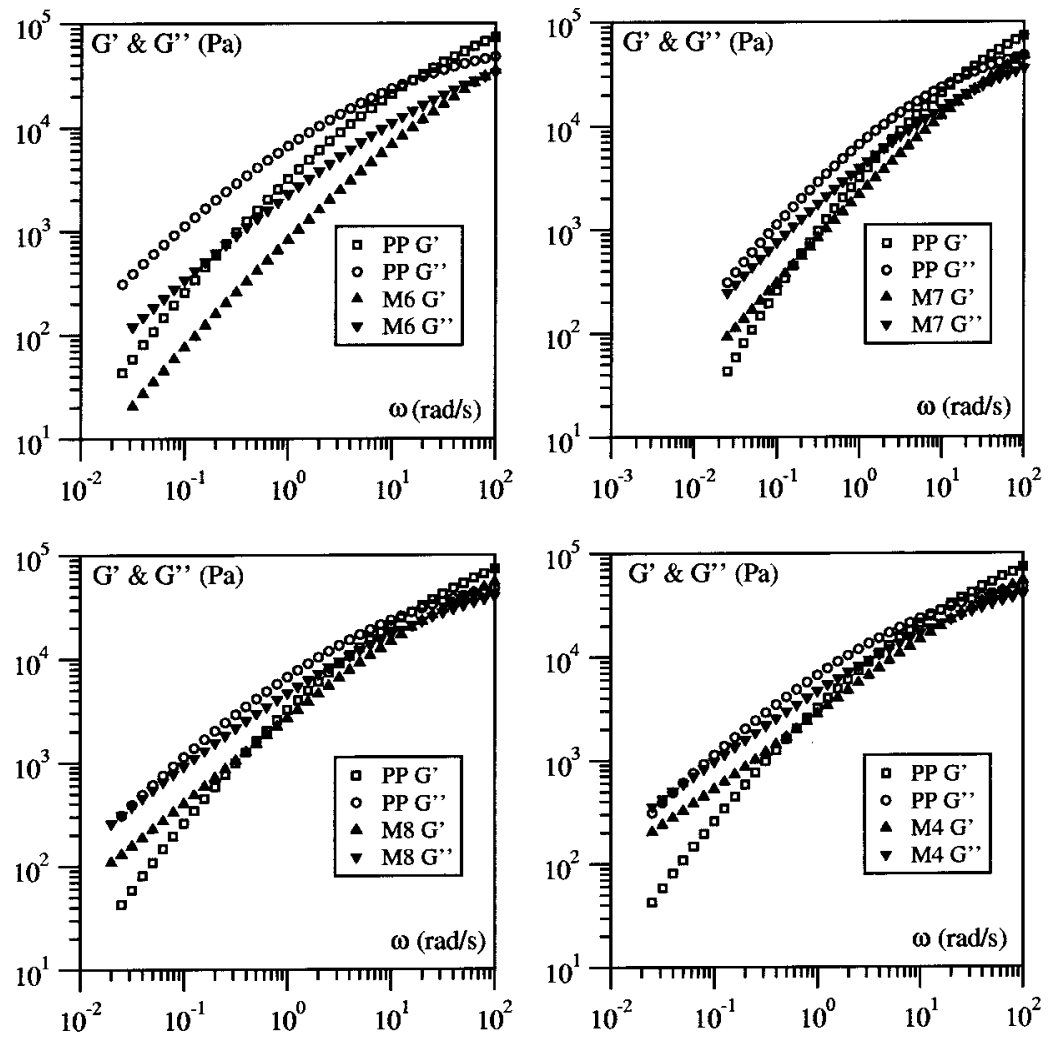

Figure 7. Dynamic moduli vs frequency. Polypropylene and polypropylene-modified $\mathrm{M} 6$ to $\mathrm{M} 8$ and $\mathrm{M} 4$ at $180{ }^{\circ} \mathrm{C}$.

Table 1. Formula of Disulfide Compounds

\begin{tabular}{|c|c|c|}
\hline Ref. & TETDS & TMTDS \\
\hline Name & tetraethyl thiuram disulfide & tetramethyl thiuram disulfide \\
\hline Formula & 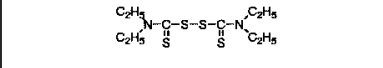 & 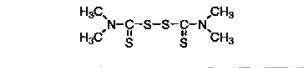 \\
\hline Ref. & BPTDS & DTBzT \\
\hline Name & bis(piperdinothiocarbonyl) disulfide & 2,2' dithiobis(benzothiazole) \\
\hline Formula & & \\
\hline
\end{tabular}

Table 2. Formulation of Modified Polypropylenes

\begin{tabular}{|c|c|c|c|c|}
\hline ref & M1 & M2 & M3 & M4 \\
\hline $\begin{array}{l}\text { DHBP }(\mathrm{g} / \mathrm{kg}) \\
\text { TMPTA }(\mathrm{g} / \mathrm{kg}) \\
\text { co-agent } \\
\text { co-agent }(\mathrm{g} / \mathrm{kg})\end{array}$ & $\begin{array}{l}0.75 \\
6 \\
\text { TETDS } \\
0.25\end{array}$ & $\begin{array}{l}0.75 \\
8 \\
\text { TETDS } \\
0.25\end{array}$ & $\begin{array}{l}0.75 \\
10 \\
\text { TETDS } \\
0.25\end{array}$ & $\begin{array}{l}0.75 \\
12 \\
\text { TETDS } \\
0.25\end{array}$ \\
\hline ref & M5 & M6 & M7 & M8 \\
\hline $\begin{array}{l}\text { DHBP }(\mathrm{g} / \mathrm{kg}) \\
\text { TMPTA }(\mathrm{g} / \mathrm{kg}) \\
\text { co-agent } \\
\text { co-agent }(\mathrm{g} / \mathrm{kg})\end{array}$ & $\begin{array}{l}0 \\
12 \\
\text { TETDS } \\
0.25\end{array}$ & $\begin{array}{l}0.75 \\
12 \\
\text { DTBzT } \\
0.25\end{array}$ & $\begin{array}{l}0.75 \\
12 \\
\text { BPTDS } \\
0.25\end{array}$ & $\begin{array}{l}0.75 \\
12 \\
\text { TMTDS } \\
0.25\end{array}$ \\
\hline
\end{tabular}

probe), with the metallic plate in contact with the polymer melt. Depending on the temperature and frequency, the strain amplitude was varied from $1 \%$ for the rubber plateau to $50 \%$ for the terminal zone. It was always verified that the behavior of the sample remained in the range of linear viscoelasticity. The experiments were carried out at $180{ }^{\circ} \mathrm{C}$.

5.3. Thermal Analysis. The thermal behavior of the different samples were determined using a differential scanning calorimeter (Netzsch DSC 200) with the following procedure: the samples (10 mg), encapsulated in aluminum pans, were heated from 25 up to $220^{\circ} \mathrm{C}$ at $10^{\circ} \mathrm{C} / \mathrm{min}$, held $4 \mathrm{~min}$ at this temperature, and then cooled to $25^{\circ} \mathrm{C}$ at the same rate.
Table 3. Crystallization Temperature of Modified Polypropylene and Polypropylenes

\begin{tabular}{lccccc}
\hline & PP & M1 & M2 & M3 & M4 \\
\hline $\mathrm{T}_{\text {c(onset })}\left({ }^{\circ} \mathrm{C}\right)$ & 118.0 & 127.0 & 130.2 & 130.5 & 130.0 \\
$\mathrm{~T}_{\mathrm{c}(\max )}\left({ }^{\circ} \mathrm{C}\right)$ & 110.4 & 120.1 & 124.6 & 124.7 & 124.3
\end{tabular}

\section{Results and Discussion}

6.1. Effect of the Cross-Linking Co-Agent Concentration. Data of storage modulus, $\mathrm{G}^{\prime}(\omega)$, and loss modulus, $G^{\prime \prime}(\omega)$, are shown in Figure 4 for the modified PP M 1 to M 4 and the plain PP. The viscoelastic behavior of these samples is characteristic of the polymer melt near the terminal zone. In the case of the reactied PP M1 to M3, the degradation of the PP induces an horizontal shift of the dynamic moduli. The data show that a second elastic plateau appears for modified PP M2 to M4 corresponding to an increase of the terminal relaxation time.

The tan $\delta$ defined by the ratio G" $/ \mathrm{G}^{\prime \prime}$ provides another way to represent these data (Figure 5). The modified PP M2 to M4, compared to the plain PP, show a decrease of $\tan \delta$ at low frequencies, $\omega<3 \mathrm{rad} / \mathrm{s}$, corresponding to an increase of the terminal relaxation time. For a polymer melt, the relaxation time is a function of the size of the macromol ecule (i.e., molecular weight, long chain branches ${ }^{66-68}$ ). We observe exactly this phenomenon with the modified PP and we assume that is due to the grafting of long chain branches onto the PP skeleton. This point can be confirmed by the thermal analysis of modified PP. We observe that the crystallization temperature increases with the concentration of TMPTA monomer (Table 3). The PP-HMS, i.e., PP with long chain branches, is characterized by an higher crystallization temperature and shorter crystallization time compared with linear PP. 13,8

The decreasing of $\tan \delta$ at low frequencies is proportional to the TMPTA concentration. At low TMPTA 


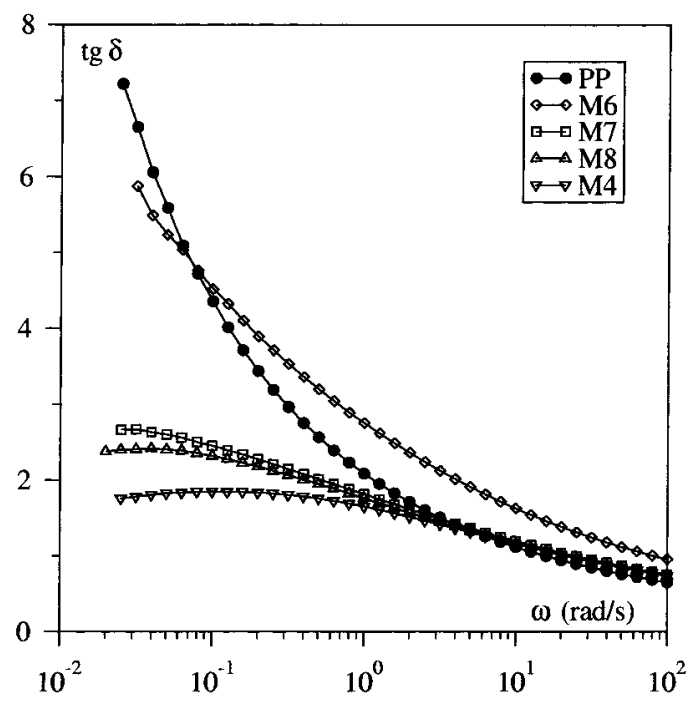

Figure 8. $\tan \delta$ vs frequency. Polypropylene and polypropylene-modified M6 to M8 \& M4 at $180{ }^{\circ} \mathrm{C}$.

concentration, typically for the M1 sample, the data show that the efficiency of branching is too low. In fact, the $\beta$-scission and the grafting of a monomer onto the backbone may occur simultaneously, and the rate of grafting depends on the monomer concentration. For a given peroxide, parameters affecting the kinetic of the $\beta$-scission reaction are its concentration, the polymer temperature, and the reaction time.

Under the experimental conditions used, the modified PP are gel-free and the homopolymerization of TMPTA is not observed. The gel content was determined by extraction in xylene for $24 \mathrm{~h}$.

6.2. Chemical Mechanism. To explain the chemical mechanism, four sulfide compounds have been used (Table 1). Without sulfide co-agent and with peroxide and monomer, we observed a strong degradation of PP prepared due to an important $\beta$-scission. In our experi- mental conditions, the TMPTA monomer does not exert any influence on the degradation of PP and the presence of sulfide conpunds is absolutely necessary to limit the scission of the PP and build the branched structure.

Nevertheless, the peroxide is necessary to obtain this structure. Figure 6 shows the dynamic behaviors of modified PP M4, with peroxide, and M5, without peroxide, compared to the plain PP. In the case of the M5 sample, no horizontal shift of the dynamic moduli was observed. This confirms the low mechanico-chemical degradation of PP. At low frequencies, an increase of the elastic modulus is observed. Its seems to us that the TMPTA monomer and the TETDS molecule allow a low grafting onto the PP backbone. The small concentration of macroradicals PP is responsible for the lower grafting.

Figures 7 and 8 show repectively the dynamic behaviors and the tan $\delta$ of modified PP M6 to M8 and M4 compared to the plain PP. According to the rheological results, the efficiency of these sulfide coumpounds is tetraethyl thiuram disulfide or TEDS > tetramethyl thiuram disulfide or TMTDS > bis(piperdinothiocarbonyl) disulfide or BPTDS > 2,2'-dithiobis(benzothiazole) or DTBzT.

The rheological behaviors of the modified PP M7, M8, and $\mathrm{M} 4$ are similar and the rheological behavior of the M6 sample shows an important degradation. Otsu has shown that the DTBzT does not have a thermal initiator in the polymerization of styrene, methyl methacrylate, etc. ${ }^{51}$ so then this molecule is not an iniferter. On the other hand, the three disulfides, TEDS, TMTDS, and BPTDS, are known as iniferter compounds.

By thermal decomposition, the thiuram disulfide gives two dithiocarbamate radicals. Lambrinos and co-workers have studied the polymerization of n-butyl acrylate with a thiuram disulfide photoinitiator. They have been found that the dithiocarbamate radical is a weak initiator of acrylate monomer. 60 It is even lower than the rate of the "spontaneous" polymerization under

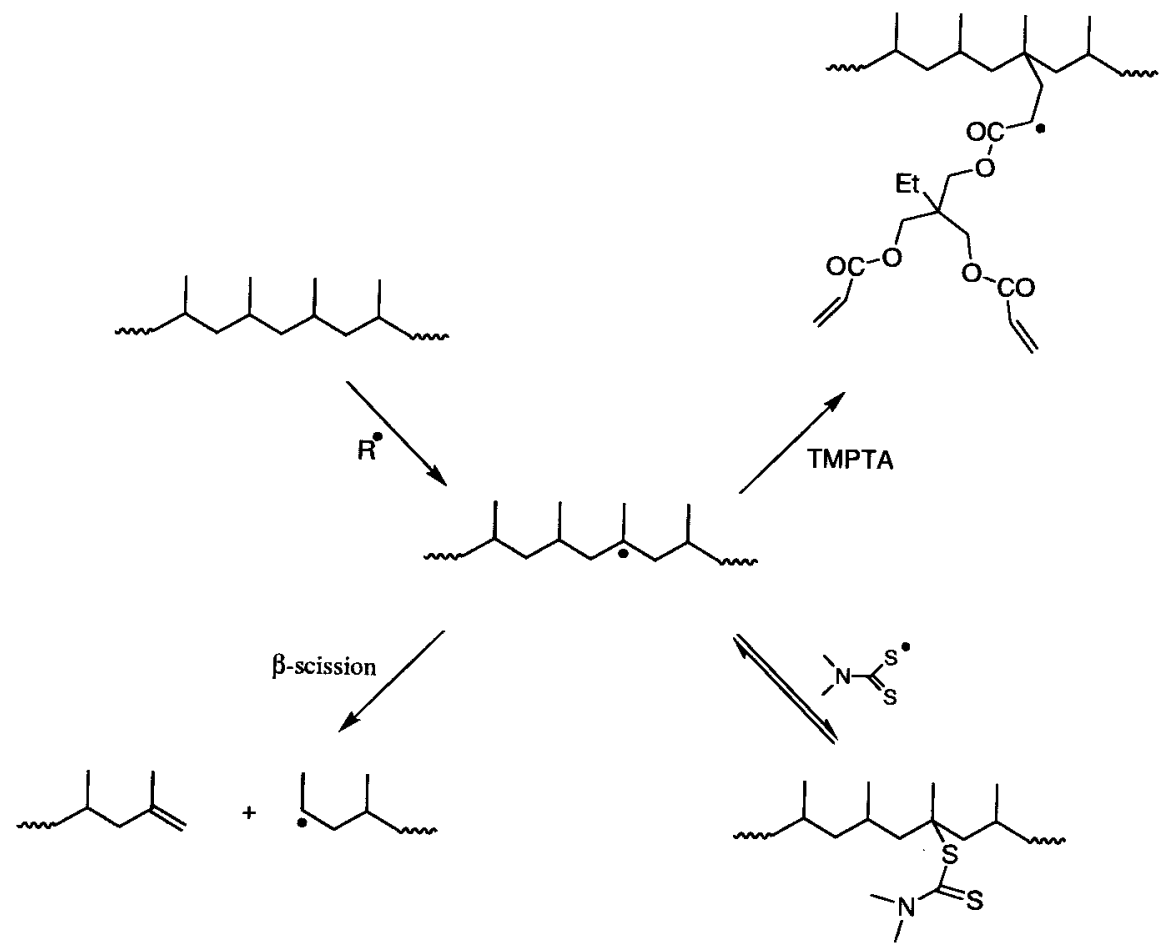

Figure 9. Chemical mechanism. 
irradiation. Consequently, the PP skeleton is not attacked by the dithiocarbamyl radicals. The presence of peroxide is strictly necessary to obtain a macroradical PP. This radical is extremely unstable at high temperature. The dithiocarbamyl radicals can be reacted with the macroradical PP, and this reaction is reversible. In fact, the dithiocarbamyl radicals cause a decrease in the instantaneous concentration of free radicals and thus limits the $\beta$-scission. This low instantaneous concentration favors the reaction between TMPTA and macroradical PP and increase the effiency of the branching. Figure 9 shows this chemical mechanism.

\section{Conclusions}

Polypropylenes with Iong chain branches were prepared using reactive extrusion. We used a polyfunctional acrylate monomer, trimethylol propane triacrylate, and a sulfide compound in the presence of peroxide, 2,5dimethyl-2,5-di(tert-butyl peroxy)hexane. When the sulfide compound is a thiuram disulfide, a long branches structure was obtained.

The dynamic moduli of the modified polypropylenes compared to the plain polypropylene show a growth of the elastic modulus corresponding to an increase of the terminal relaxation time. This confirms the presence of the long chain branches onto the polypropylene skel eton. The rate of branching is proportional to the TMPTA concentration.

The chemical mechanism was investigated with four sulfide compounds. Only the iniferter molecules allow to obtained the branched structures. The dithi ocarbamate radicals can be reacted with the macroradical PP and this reaction is reversible. These radicals induce a decrease in the instantaneous concentration of free radicals, and thus limits the $\beta$-scission. This favors the reaction between TMPTA and macroradical PP and increases the effiency of the branching.

Acknowledgment. The author is pleased to acknowledge the Solvay Co. for a financial contribution to this research.

\section{References and Notes}

(1) Naguib, H. E.; Xu, J . X.; Park, C. B.; Hesse, A.; Panzer, U.; Reichelt, N. SPE Annu. Tech. Conf. 2001, 2269.

(2) Koyama, K.; Sugimoto, M. XIIIth International Congress on Rheol ogy; 2000; p 3-409.

(3) Larson, R. Constitutive equations for polymer melts and solutions; Butterworth Series in Chemical Engineering; Butterworth, London, 1988; 208.

(4) Bastian, H.; Wagner, H. M. XIIIth I nternational Congress on Rheol ogy 2000; p 1-309.

(5) Graebling, D.; Lambla, M.; Wautier, H. J . Appl. Polym. Sci. 1997, 66, 809

(6) Yoo, M. J .; Done, D. SPE Annu. Tech. Conf. 1992, 569.

(7) Drickman, M. R.; McHugh, K. E. SPE Annu. Tech. Conf. 1992, 496.

(8) Phillips, E. M.; McHugh, K. E.; Ogale, K.; Bradley, M. B. Kunstst. Ger. Plast. 1992, 82(8), 23.

(9) Lesca, G.; Romanini, D.; Vezzoli, A. US Patent 5,324,753, 1994.

(10) Lesca, G.; Romanini, D.; Vezzoli, A. US Patent 5,338,764, 1994.

(11) Robeson, L. V. US Patent 5,368,919, 1994

(12) Hingmann, R.; Marczinke, B. L. J . Rheol. 1994, 38, 573.

(13) Gaylord, N. G.; Katz, L.; Park, J . P. World Patent 91/13933, 1991.

(14) Mestanza, R.; Graebling, D.; Lambla, M. European Patent 0754 711, 1996; US Patent 6,020,437, 2000.

(15) Chodák, I.; Fabianová, K.; Borsig, E.; Lazár, M. Angew. Makromol. Chem. 1978, 69, 107.
(16) Borsig, E.; Fiedlerova, A.; Lazár, M.J . Macromol. Sci.-Chem. 1981, A16, 513

(17) Xiaochun, W.; Tzoganakis, C.; Rempel, G. L. J . Appl. Polym. Sci. 1996, 61, 1395.

(18) Chodák, I.; Zimányová, E. Eur. Polym. J . 1984, 20, 81.

(19) Ŝimúkovă, D.; Rado; R.; Veisovâ, E. Przem. Chem. 1964, 43, 167 (in Slovak, with summary in English).

(20) Čapla, M.; Borsig, E.; Lazár, M. A. Makromolekul. Chem. 1985, 133, 53.

(21) Borsig, E.; Čapla, M.; Fiedlerova, A.; Lazár, M. Polym. Commun. 1990, 31, 293

(22) Yu, Q.; Zhu, S. Polymer 1999, 40, 2961.

(23) DeNicola, A. J. J r. European Patent 0384 431, 1990.

(24) Scheve; B. J .; Mayfield, J . W.; DeNicola, A.J ., J r. US Patent 4,916,198, 1990. DeNicola, A. J., J r.; Smith, J. A.; Felloni, M. US Patent 5,414,027, 1995. DeNicola, A. J ., J r.; Smith, J . A.; Felloni, M. US Patent 5,541,236, 1996. Scheve; B. J . Mayfield, J. W.; DeNicola, A. J ., J r. US Patent 5,554,668, 1996. Scheve; B. J .; Mayfield, J . W.; DeNicola, A. J ., J r. US Patent 5,591,785, 1997. DeNicola, A. J ., J r.; Smith, J . A.; Felloni, M. US Patent 5,605,936, 1997. Scheve; B. J.: Mayfield, J. W.; DeNicola, A. J ., J r. US Patent 5,731,362, 1998. Dang, V. A.; Dong, D. US Patent 6,225,411, 2001. Dang, V. A.: Dong, D. US Patent 6,306,970, 2001.

(25) Lucas, B. M.; Krishnamurthy, V.; Bonser J . R. US Patent 5,439,949, 1995.

(26) Saito, J .; Kikukawa, S.; Makuuchi, K.; Yoshii, F. US Patent 5,560,886, 1996.

(27) Braga, V.; Ghisellini, R. European Patent 0450 342, 1991.

(28) Romani, F.; Corrieri, R.; Braga, V.; Ciardelli, F. Polymer 2002 $43,1115$.

(29) Yu, D. W.; Dey, S. K.; Pringgosusanto, F.; Xanthos, M. SPE Annu. Tech. Conf. 2000, 399.

(30) van Swieten, A. P.; Waanders, P. P.; Meijer, J .; Hogt, A. H. World Patent 00/08072, 2000.

(31) van de Bovenkamp-Bouwman, A. G.; Meijer, J .; Syed, E. A.; Hogt, A. H.; de Vries, B. World Patent 00/09478, 2000.

(32) Gotsis, A. D.; Lagendijk, R. P.; Hogt, A. H. XIIIth International Congress on Rheology; 2000; $p$ 1-203.

(33) Lagendijk, R. P.; Hogt, A. H.; Buijtenhuijs, A.; Gotsis, A. D. Polymer 2001, 42, 10035

(34) Lu, B.; Chung, T. C. Macromolecules 1999, 35, 8678

(35) Borsig, E.; Fiedlerová, A.; Rychlá, L.; Lazár, M.; Rätzsch, M.; Haudel, G. J . Appl. Polym. Sci. 1989, 37, 467.

(36) Yu, D. W.; Xanthos, M.; Gogos, C. G. Adv. Polym. Technol. 1990, 10, 163

(37) Chodák, I.;J anigova, I.; Romanov, A. Makromol. Chem. 1991 192, 2791.

(38) Zamotaev, P.; Chodák, I.; Mityukhin, O.; Chorvath, I. J . Appl Polym. Sci. 1995, 56, 935.

(39) Tselios, Ch.; Bikiaris, D.; Maslis, V.; Panayiotou, C. Polymer 1998, 39, 6807

(40) Lambla, M.; Graebling, D. European Patent 0686 664, 1995.

(41) Otsu, T.; Yoshida, M. Makromol. Chem. Rapid Commun. 1982, 3, 127.

(42) Otsu, T.; Kuriyama, A. Polym. J. 1985, 17, 97

(43) Boutevin, B. Adv. Polym. Sci. 1990, 94, 70.

(44) J erome, R.; Henrioulle-Granville, M.; Boutevin, B.; Robin, J . Prog. Polym. Sci. 1991, 16, 837.

(45) Chapman, A. V.; Porter, M. Sulphur vulcanization chemistry. In Natural Rubber Sciences and Technology; Roberts, A. D. Ed.; Oxford Science Publications: Oxford, England, 1988.

(46) Ferrington, T. E.; Tobolsky, A. V. J . Am. Chem. Soc. 1955 77, 4510

(47) Kern, R. J . J . Am. Chem. Soc. 1955, 77, 1382

(48) Otsu, T. J. Polym. Sci. 1957, 26, 236.

(49) I moto, M.; Otsu, T.; Yonezawa, J. Makromol. Chem. 1960 $36,93$.

(50) Ferrington, T. E.; Tobolsky, A. V. J . Am. Chem. Soc. 1958 80, 3215.

(51) Otsu, T.; Nayatani, K.; Muto, I.; I mai, M. Makromol. Chem 1958, 27, 142.

(52) Otsu, T.; Nayatani, K. Makromol. Chem. 1958, 27, 149

(53) Barton, A. F.; Bevington, J. C. Makromol. Chem. 1963, 68 216

(54) Barton, A. F.; Bevington, J . C. Trans. Faraday Soc. 1966, $62,433$.

(55) Otsu, T.; Yoshida, M.; Tazaki, T. Makromol. Chem. Rapid Commun. 1982, 3, 133.

(56) Otsu, T.; Yoshida, M.; Kuriyama, A. Polym. Bull. (Berlin) $1982,7,45$

(57) Kuriyama, A.; Otsu, T. Polym. J . 1984, 16, 511

(58) Otsu, T.; Kuriyama, A. Polym. Bull. (Berlin) 1984, 11, 1984. 
(59) Otsu, T.; Kuriyama, A. J . Macromol. Sci.-Chem. 1984, A21, 961.

(60) Lambrinos, P.; Tardi, M.; Polton, A.; Sigwald, P. Eur. Polym. . 1990, 26, 1125 .

(61) Greszta, D.; Mardare, D.; Matyjaszewski, K. Macromol ecules 1994, 27, 638 .

(62) Moore, C. G.; Saville, B.; Watson, A. A. J . Appl. Polym. Sci. $1960,3,373$

(63) Coleman, M. M.; Shelton, J . R.; Koenig, J . L. Rubber Chem. Technol. 1973, 46, 938.

(64) Coleman, M. M.; Shelton, J . R.; Koenig, J . L. Rubber Chem.
Technol. 1973, 46, 957.

(65) Ducháček, V. J . Appli. Polym. Sci. 1978, 22, 227.

(66) Graessley, W. W. Adv. Polym. Sci. 1982, 47, 67.

(67) Doi, M.; Edwards, S. F. The Theory of Polymer Dynamics; Oxford Science Publications, Clarendon Press: Oxford, England, 1994.

(68) Vega, J . F.; Santamaria, A.; Muñoz-Escalona, A.; Lafuente, P. Macromol ecules 1998, 31, 3639.

MA0109469 